\title{
ģFORSETI
}

Forseti. Revista de Derecho. Volumen 7, № 10, Lima, 2019, pp. 93 - 115

\section{El control difuso en sede arbitral}

\author{
Los parámetros constitucionales que se deben seguir según la jurisprudencia del \\ Tribunal Constitucional
}

\section{Reynaldo Bustamante Alarcón*}

\begin{abstract}
Resumen. - En este trabajo se presentan los parámetros constitucionales que, según la jurisprudencia del Tribunal Constitucional peruano, deben seguir los árbitros en el ejercicio del control difuso de la constitucionalidad de las leyes, al resolver las controversias que conozcan en el marco de un arbitraje. Un poder-deber de controlar la constitucionalidad normativa que el Tribunal Constitucional extendió a los árbitros jurisprudencialmente. Lo que se busca es contribuir a que los operadores arbitrales cuenten con instrumentos útiles para abordar este tipo de control, independientemente de la posición que se asuma sobre la conveniencia o corrección de extender el control difuso al ámbito del arbitraje.
\end{abstract}

Abstract. - The following article showcases constitutional criteria that arbitrators, according to the Peruvian Constitutional Court's jurisprudence, should follow within use of diffuse control of legal constitutionality whenever facing controversies in arbitrations. A faculty but also the obligation to control norms the Constitutional Court extends to arbitrators though jurisprudence. Therefore, the aim is to reinforce use these standards to arbitral operators and encourage their use when considering to apply this type of control, unrestrained from their position of convenience or conviction to the extension of diffuse control in arbitration.

Palabras claves. - Arbitraje, control difuso, laudo, Constitución, Tribunal Constitucional.

Keywords. - Arbitration, diffuse control, award, Constitution, Constitutional Court. 


\section{Introducción}

El arbitraje ha alcanzado un importante desarrollo. Su flexibilidad y rapidez para la solución y prevención de conflictos de naturaleza patrimonial (en comparación con el tradicional proceso judicial) explican en buena medida su continua y creciente acogida. Lo vemos en el ámbito privado (por ejemplo, en la solución de conflictos comerciales), en múltiples facetas de las relaciones con el Estado (es el caso de los arbitrajes de inversión y de contratación estatal) e incluso en áreas que tradicionalmente eran de conocimiento exclusivo del Poder Judicial (el arbitraje laboral económico es una muestra de ello). Bien puede decirse que el arbitraje ha pasado de ser una institución de exclusivo interés privado (en el sentido que solo atañe a las partes que hacen uso de él) para pasar a ser una institución que, además, es de interés público (en el sentido que nos incumbe a todos por la importancia que tiene en diversos ámbitos de la vida social). En el caso peruano esta impronta tiene una elevada expresión en el reconocimiento constitucional que el arbitraje ha alcanzado: el artículo $139^{\circ}$, inciso 1 , de la Constitución lo califica como una "jurisdicción" independiente frente al Poder Judicial. Un reconocimiento que lo fortalece al otorgarle el máximo grado de protección jurídica, pero que al mismo tiempo genera una serie de problemas que, mal abordados, podrían terminar desnaturalizándolo, sino debilitándolo.

Uno de esos problemas guarda relación con el control difuso de la constitucionalidad de las leyes, es decir, con el poder-deber que el artículo $138^{\circ}$ de la Constitución atribuye a los jueces para no aplicar, al caso concreto, la norma legal que resulte incompatible con la Constitución. Nuestro Tribunal Constitucional ha establecido jurisprudencialmente que los árbitros pueden y deben ejercer ese tipo de control. Lo explica de esta manera: "Siendo el arbitraje una jurisdicción independiente [...], y debiendo toda jurisdicción poseer las garantías de todo órgano jurisdiccional (como las del Poder Judicial), es consecuencia necesaria de ello que la garantía del control difuso de constitucionalidad, prevista en el segundo párrafo del artículo $138^{\circ}$ de la Constitución pueda también ser ejercida por los árbitros en la jurisdicción arbitral, pues el artículo $138^{\circ}$ no puede ser objeto de una interpretación constitucional restrictiva y literal, como exclusiva de la jurisdiccional ordinaria o constitucional"1.

Ciertamente la referencia a una autoridad (con todo lo valiosa que puede ser en un juicio de validez jurídica donde la competencia aparece como uno de sus criterios) no es suficiente para concluir que un problema se encuentra adecuadamente resuelto. De hecho la citada postura del Tribunal Constitucional solo tiene coherencia y especial sentido dentro del marco que supone la concepción del Estado constitucional de Derecho (donde ostenta supremacía la Constitución, a diferencia del Estado de Derecho decimonónico, donde es la ley la que ejerce tal condición). Fuera de ese marco la postura del Tribunal Constitucional sería

1 Sentencia del Tribunal Constitucional. Exp. N 142-2011-PA/TC, fundamento 24. 
indebidamente analizada pues perdería los presupuestos teóricos y normativos que le sirven de sustento (como ocurriría, por ejemplo, si se le analiza desde la concepción del Estado de Derecho legislativo donde la ley es la "soberana" y en donde la Constitución solo aparece como una carta de organización política). Dentro de ese marco, las decisiones de este alto Tribunal son importantes dada la calidad de intérprete supremo de la Constitución que ostenta (calidad derivada de los artículos $201^{\circ}$ y $202^{\circ}$ de la Norma Fundamental y declarada expresamente en el artículo $1^{\circ}$ de su Ley Orgánica). Una supremacía que confiere a sus decisiones un carácter especialmente vinculante y una protección reforzada (lo reconocen expresamente los artículos VI y VII del Título Preliminar del Código Procesal Constitucional).

Sin perjuicio de ello, son varios los problemas que se pueden generar al extender a los árbitros el control difuso de la constitucionalidad de las leyes; problemas que deben ser adecuadamente analizados para determinar sus consecuencias en el ordenamiento jurídico y proponer sus posibles soluciones. A título de ejemplo, debería analizarse si la posibilidad de que los árbitros ejerzan este tipo de control incrementa los problemas de coherencia o racionalidad del sistema jurídico, o si este es un paradigma que la Teoría del Derecho contemporánea debería seguir matizando. Sería conveniente profundizar también en el papel que le corresponde al Poder Judicial y al Tribunal Constitucional frente a un tribunal arbitral, a propósito de este tipo de control (por ejemplo, para examinar en qué medida pueden revisar lo resuelto por los árbitros cuando ejercen el control difuso, o qué margen de actuación tienen los árbitros frente a los precedentes constitucionales, los precedentes judiciales o la doctrina jurisprudencial que dichos organismos estatales generan). La supuesta tensión entre Constitución y democracia $-\mathrm{o}$, si se prefiere, entre el principio de mayorías y las normas constitucionales como límites al poder- debería ser también objeto de examen. No debe perderse de vista que en una sociedad democrática la ley es expresión de derechos políticos que, en virtud de la Constitución, están en el mismo plano que los otros derechos y principios constitucionales. Menos debe olvidarse que una Constitución pluralista está llena de una serie de principios y derechos que, por su naturaleza abierta, muchas veces son objeto de regulación legislativa, dentro del marco de las opciones que razonablemente otorga el pluralismo de la Constitución; por lo tanto, si bien en caso de contradicción la ley debe ceder frente a la norma constitucional, también es verdad que deben determinarse los parámetros a seguir por cualquier órgano que ejerza el control de la constitucionalidad normativa (en este caso, un tribunal arbitral) para no caer en el extremo de "despolitizar" la ley, invadiendo las esferas del legislador, o degradándola a mera función técnica para la actuación de los contenidos constitucionales, por más elevados y seductores que estos puedan ser. Un peligro que se agudiza en el arbitraje si se tiene en cuenta que, a diferencia de los jueces del Poder Judicial, los árbitros no se encuentran integrados en una institución organizada según criterios de jerarquía, complementariedad y coordinación; situación que dificulta la generación de mecanismos que procuren la uniformidad de las decisiones arbitrales o que permitan revisarlas si brindan 
soluciones contradictorias ante casos sustancialmente idénticos. En tal escenario, resulta patente que el componente político de la ley, e incluso su fuerza normativa, se vería seriamente debilitada ante la posibilidad de que el control difuso se ejerza en los innumerables arbitrajes que se puedan iniciar. Sin que acabe el listado de los problemas que genera el control difuso en sede arbitral, debería analizarse además los argumentos que niegan legitimidad democrática a los órganos jurisdiccionales, y con mayor razón a los cuasi jurisdiccionales (como es el caso de los tribunales arbitrales), para ejercer el control de la constitucionalidad de las normas dictadas por los órganos democráticamente elegidos.

En el presente trabajo abordaremos uno de esos problemas. Como quiera que la posibilidad de que los árbitros ejerzan el control difuso de la constitucionalidad de las leyes se encuentra ampliamente reconocida por la jurisprudencia de nuestro Tribunal Constitucional, presentaremos aquí los parámetros constitucionales que, según la jurisprudencia de este alto Tribunal, deben cumplir los árbitros $-\mathrm{y}$, en general, cualquier órgano jurisdiccional- para ejercer válidamente este tipo de control. Lo haremos sin perjuicio de la posición que cada quien asuma sobre la conveniencia o inconveniencia de extender a los árbitros el control difuso de la constitucionalidad de las leyes y/o sobre la corrección o incorrección de esta extensión desde un punto de vista teórico. Lo que pretendemos con esta delimitación material es contribuir a que los operadores arbitrales cuenten con instrumentos útiles para abordar el control difuso de la constitucionalidad de las leyes, dejando a salvo el análisis de otros problemas ocasionados por la ampliación de este tipo de control al ámbito del arbitraje; problemas que sin ánimo taxativo han sido anteriormente enunciados. Un análisis que, por respeto a la delimitación material y a la extensión concedida para el desarrollo de este trabajo, no puede ser abordado en estas líneas.

\section{Los parámetros constitucionales del control difuso en sede arbitral}

El Tribunal Constitucional ha establecido en reiterada jurisprudencia los parámetros constitucionales que deben respetar los árbitros al ejercer el control difuso de la constitucionalidad de las leyes. Bien vistas las cosas esos parámetros no solo rigen el control difuso en sede arbitral sino también en sede judicial porque el fundamento y el objetivo que se persigue con este tipo de control son comunes en ambas sedes. Una de las expresiones de esa jurisprudencia es el precedente vinculante contenido en la STC N ${ }^{\circ}$ 142-2011-PA/TC, donde este alto Tribunal señaló: "El control difuso de la jurisdicción arbitral se rige por las disposiciones del artículo VI del Título Preliminar del Código Procesal Constitucional y la jurisprudencia vinculante dictada por este Tribunal Constitucional sobre el control difuso. Solo podrá ejercerse control difuso de constitucionalidad sobre una norma aplicable al caso de la que dependa la validez del laudo arbitral, siempre que no sea posible obtener de ella una interpretación conforme a la Constitución y además, se verifique la existencia de un perjuicio claro y directo al derecho de 
alguna de las partes" 2 . Sobre esa base, los parámetros constitucionales que, según la jurisprudencia del Tribunal Constitucional, rigen el ejercicio del control difuso en sede arbitral son los siguientes:

\section{i. El control difuso debe realizarse en armonía con la jurisprudencia del Tribunal Constitucional}

Conforme al precedente constitucional anteriormente citado, el control difuso que ejercen los árbitros se rige por el artículo VI del Título Preliminar del Código Procesal Constitucional, así como por la jurisprudencia vinculante sobre ese tipo de control dictada por el Tribunal Constitucional. En consecuencia, por aplicación extensiva de este artículo legal (que se realiza de conformidad con dicho precedente) los árbitros -además de los jueces- "interpretan y aplican las leyes o toda norma con rango de ley y los reglamentos según los preceptos y principios constitucionales, conforme a la interpretación de los mismos que resulte de las resoluciones dictadas por el Tribunal Constitucional". Esto significa que los árbitros se encuentran vinculados a las resoluciones (jurisprudencia y precedentes vinculantes) que emita el Tribunal Constitucional en la interpretación de la Constitución y de las leyes. Una consecuencia coherente con la calidad de intérprete supremo de la Constitución, que ostenta este alto Tribunal; calidad que -como se ha adelantado- deriva de los artículos $201^{\circ}$ y $202^{\circ}$ de nuestra Carta Fundamental y es reconocida en el artículo $1^{\circ}$ de su Ley Orgánica: “El Tribunal Constitucional es el órgano supremo de interpretación y control de la constitucionalidad [...]. Se encuentra sometido solo a la Constitución y a su Ley Orgánica $[\ldots]^{\prime \prime}$.

Por consiguiente, cuando este alto Tribunal resuelve un asunto en determinado sentido, por ejemplo, confirmando la constitucionalidad de una ley, los árbitros y los jueces o cualquier otra autoridad- no pueden dejar de aplicar esa decisión, ni apartarse de la interpretación realizada por él; a menos, claro está, que se demuestre argumentativa y motivadamente que el caso que se conoce es sustancialmente diferente, por lo menos en algún punto significativo, al caso que conoció y resolvió el Tribunal Constitucional. Así lo exhorta el mismo Tribunal al referirse a la vinculación que ejerce sobre la justicia ordinaria: “El juez ordinario [y por la misma razón, el árbitro] no puede ampararse en su independencia para desvincularse de las sentencias del Tribunal Constitucional, pues ello significaría, en último término, una vulneración de la propia Constitución. [...]; su desconexión con la interpretación de la Constitución que haya realizado el Tribunal Constitucional [...] resultaría claramente inadmisible y supondría una indudable violación de la supremacía jurídica constitucional. Y ello porque la calificación de última ratio de lo que es o no constitucional radica en el Tribunal Constitucional, como supremo intérprete de la Constitución”3. Y en otro momento, agrega: “[...] la posición constitucional de este Colegiado respecto al Poder Judicial [y por la

Ibíd., fundamento 26.

Sentencia del Tribunal Constitucional. Exp. N 00006-2006-CC/TC, fundamentos 46 y 47. 
misma razón, respecto de los árbitros o cualquier otra autoridad o persona], en tanto que es consecuencia de lo que la propia Constitución y la ley establecen, no puede ser objeto de cuestionamiento alguno bajo una interpretación formalista del principio de separación de poderes (artículo $43^{\circ}$ ) y de la autonomía e independencia al que hacen referencia los artículos $138^{\circ}$ y $139^{\circ}$ de la Constitución. Autonomía que, según jurisprudencia reiterada de este Colegiado (vid. por ejemplo STC 0015-2005-AI, fundamento 7) no debe confundirse con autarquía, pues desde el mismo momento en que aquella le viene atribuida por la Constitución, su desarrollo debe realizarse con respeto pleno a ese ordenamiento jurídico. La posición constitucional que ostenta el Tribunal no está ni puede estar, por tanto, librada a la voluntad de algunos jueces [o árbitros u otra autoridad] de respetar o no el lugar que ocupa el supremo intérprete de la Constitución en nuestro ordenamiento jurídico" 4 .

No debe perderse de vista que en el ordenamiento jurídico peruano el Tribunal Constitucional puede emitir una forma especial de decisiones denominada "precedente vinculante", "precedente constitucional" o "precedente constitucional vinculante". Como explica este alto Tribunal, "el precedente constitucional vinculante es aquella regla jurídica expuesta en un caso particular y concreto que el Tribunal Constitucional decide establecer como regla general; y, que, por ende, deviene en parámetro normativo para la resolución de futuros procesos de naturaleza homóloga" 5 . Y agrega: "El precedente constitucional tiene por su condición de tal efectos similares a una ley. Es decir, la regla general externalizada como precedente a partir de un caso concreto se convierte en una regla preceptiva común que alcanzar a todos los justiciables y que es oponible frente a los poderes públicos" 6 . En ese sentido, añade, "la fijación de un precedente constitucional significa que ante la existencia de una sentencia con unos específicos fundamentos o argumentos y una decisión en un determinado sentido, será obligatorio resolver los futuros casos semejantes según los términos de dicha sentencia"7. Esta competencia del Tribunal Constitucional para emitir precedentes vinculantes se encuentra establecida en el artículo VII del Título Preliminar del Código Procesal Constitucional que dice: "Las sentencias del Tribunal Constitucional que adquieren la autoridad de cosa juzgada constituyen precedente vinculante cuando así lo exprese la sentencia, precisando el extremo de su efecto normativo. Cuando el Tribunal Constitucional resuelva apartándose del precedente, debe expresar los fundamentos de hecho y de derecho que sustentan la sentencia y las razones por las cuales se aparta del precedente".

Con el propósito de esclarecer las similitudes y diferencias entre la jurisprudencia y el precedente vinculante, el Tribunal Constitucional precisa: “La jurisprudencia

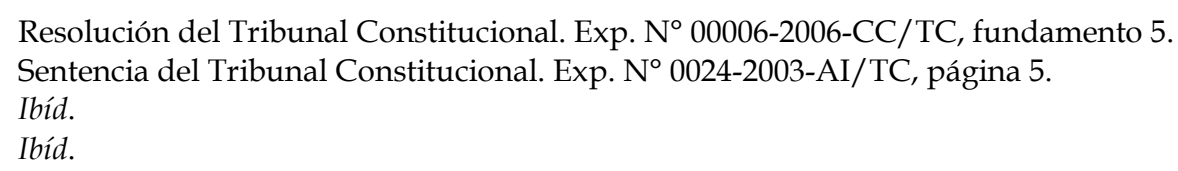


constituye [...] la doctrina que desarrolla el Tribunal en los distintos ámbitos del [D]erecho, a consecuencia de su labor frente a cada caso que va resolviendo"; "si $^{2}$ bien tanto la jurisprudencia como el precedente constitucional tienen en común la característica de su efecto vinculante, en el sentido de que ninguna autoridad, funcionario o particular puede resistirse a su cumplimiento obligatorio, el Tribunal, a través del precedente constitucional, ejerce un poder normativo general, trayendo una norma a partir de un caso concreto" 8 . De lo expuesto se sigue que, mientras la jurisprudencia constitucional vinculante se configura por los criterios uniformes que el Tribunal Constitucional mantiene, en distintas resoluciones, sobre un mismo asunto de relevancia constitucional; el precedente vinculante se configura, en cambio, en una sola sentencia, en donde el mismo Tribunal identifica un criterio como precedente y, por tal razón, pasa a tener este unos efectos normativos similares a los de una ley.

El propio Tribunal Constitucional ha señalado que "el uso de los efectos normativos y la obligación de aplicación de un precedente vinculante depende de": 1) "la existencia de similitudes fácticas [mas no de diferencias] entre el caso a resolver y aquél del que emana el precedente"; y 2) "la existencia de similitudes y diferencias fácticas; las que en el caso de estas últimas no justifican un trato jurídico distinto", por lo que -agrega- "es factible que a través del razonamiento analógico se extienda la regla del precedente vinculante" 9 . Siendo esto así, como bien señala la doctrina especializada, frente a un precedente constitucional vinculante, comparado con el nuevo caso que un tribunal o juzgador debe resolver, este tiene solo tres posibilidades: "(1) aplicar (apply) la regla del precedente, ello cuando se trate de dos litigios verdaderamente similares; (2) seguir (follow) la regla del precedente, cuando a pesar de que existen diferencias relevantes entre los dos casos, a juicio del tribunal, estas no justifican un trato jurídico distinto y, por tanto, extiende, a través del razonamiento analógico, la regla del precedente al nuevo supuesto; o bien (3) distinguir (distinguish) la regla del precedente, esto es, no aplicarla en el asunto que resuelve y crear una nueva regla, cuando a criterio del tribunal las diferencias entre ambos casos son significativas y merecen un trato jurídico distinto" 10 .

Lo expuesto vale también para la jurisprudencia vinculante -pues, en aplicación del principio de igualdad, donde hay la misma razón hay el mismo derecho- con la precisión de que lo que vincula en el caso de la jurisprudencia, más allá de los procesos donde se emitieron las resoluciones que la configuran, no es la parte resolutiva propiamente dicha, ni las razones accidentales sino las razones determinantes que justifican esa resolución (la llamada ratio decidendi). Efectivamente, como señala el Tribunal Constitucional, "la estructura interna de sus decisiones se compone de los siguientes elementos: la razón declarativa-

\footnotetext{
Sentencia del Tribunal Constitucional. Exp. N 3741-2004-AA/TC, fundamentos 42-43.

Sentencia del Tribunal Constitucional. Exp. N0024-2003-AI/TC, página 8.

10 MAGALONI, Ana Laura. El precedente constitucional en el sistema judicial norteamericano, Madrid: McGraw Hill, 2001, p. 84.
} 
teológica, la razón suficiente (ratio decidendi) la razón subsidiaria o accidental (obiter dicta), la invocación preceptiva y la decisión o fallo constitucional (decisum)"11 Esta distinción es muy importante porque, conforme lo recuerda el mismo Tribunal, "dentro de la motivación hay que ubicar la denominada ratio decidendi -o "hilo lógico" del razonamiento de los jueces-, que comprende en los sistemas del common law tanto el principio de derecho como el hecho relevante considerado por el Juez (holding), como también las denominadas obiter dicta o razones subsidiarias. Son las razones decisivas para el caso las que vinculan, mas no las consideraciones tangenciales o de aggiornamento (obiter dicta)"12. Y continuando con la explicación, indica: "La razón suficiente [ratio decidendi] expone una formulación general del principio o regla jurídica que se constituye en la base de la decisión específica, precisa o precisable, que adopta el Tribunal Constitucional. [...] esta se constituye en aquella consideración determinante que el Tribunal Constitucional ofrece para decidir estimativa o desestimativamente una causa de naturaleza constitucional; vale decir, es la regla o principio que el Colegiado establece y precisa como indispensable y, por ende, como justificante para resolver la litis. Se trata, en consecuencia, del fundamento directo de la decisión"13. Por lo tanto, al identificar la ratio decidendi de cierta jurisprudencia del Tribunal Constitucional, es esa razón principal la que resulta vinculante a los demás jueces y autoridades, mas no las consideraciones tangenciales $\mathrm{u}$ obiter dicta.

\section{ii. La norma objeto de control debe ser relevante para la solución del caso y suponer un potencial perjuicio, claro y directo, para alguna de las partes}

El Tribunal Constitucional ha "modulado" -según sus propios términos- el ejercicio del control difuso en sede arbitral "con el propósito de que cumpla debidamente su finalidad de garantizar la primacía de la Constitución y evitar así cualquier desviación en el uso de este control constitucional"14. Para tal efecto, además de instituir como precedente vinculante que el control difuso en sede arbitral se rige por el artículo VI del Título Preliminar del Código Procesal Constitucional, así como por la jurisprudencia sobre este tipo de control dictada por aquel alto Tribunal (parámetro que fue desarrollado en el punto anterior), seguidamente ha establecido, con el mismo carácter de precedente vinculante, que "solo podrá ejercerse el control difuso de constitucionalidad sobre una norma aplicable al caso de la que dependa la validez del laudo arbitral, siempre que no sea posible obtener de ella una interpretación conforme a la Constitución y además, se verifique la existencia de un perjuicio claro y directo respecto al derecho de alguna de las partes" 15 .

\footnotetext{
Sentencia del Tribunal Constitucional. Exp. N 0024-2003-AI/TC, página 3.

Sentencia del Tribunal Constitucional. Exp. N 006-2006-PC/TC, fundamento 40.

Sentencia del Tribunal Constitucional. Exp. Nº024-2003-AI/TC, página 3.

Sentencia del Tribunal Constitucional. Exp. N 142-2011-PA/TC, fundamento 26.

Idem.
} 
Según esta precisión del Tribunal Constitucional, la norma legal susceptible de control difuso en sede arbitral no puede ser cualquier tipo de norma; debe ser: 1) "una norma aplicable al caso", y 2) "de la que dependa la validez del laudo arbitral"16. Lo primero es una obviedad: si la norma no es aplicable al caso, es decir, si no guarda una relación lógico-jurídica con la controversia, es evidente que no tiene sentido someterla a un control difuso porque esa norma no tendría que aplicarse; no por una supuesta incompatibilidad con la Constitución -que ni siquiera sería necesario examinar- sino por su impertinencia para resolver la controversia.

Lo segundo requiere mayor reflexión. Resulta patente que al Tribunal Constitucional no le basta que la norma sea pertinente al caso para que pueda ser objeto de control difuso. Es necesario, además, que sea una norma relevante para su solución. Una norma es relevante si el sentido de la decisión que se adopte como solución de un caso concreto depende de la aplicación o no aplicación de esa norma; es decir, cuando por el solo hecho de aplicarse la norma, la solución del caso sería distinta. Siendo esto así, resulta claro que toda norma relevante es además pertinente, pero no toda norma pertinente es relevante para solucionar una controversia. En parámetros de la jurisprudencia del Tribunal Constitucional, no se podría ejercer, entonces, el control difuso sobre una norma que no sea relevante para la solución de un caso. Una proposición que, debido a su origen común, vale tanto para el control difuso que se ejerce en sede arbitral como en sede judicial, razón por la cual no hay hasta aquí modulación alguna.

El problema se presenta cuando el Tribunal Constitucional asocia esa relevancia con la validez. Lo hace al decir que el control difuso en el arbitraje solo procede sobre una norma de la que dependa la "validez del laudo". Corresponde preguntar qué debemos entender por esta expresión. ¿Debemos circunscribirla a los requisitos de validez del laudo previstos en la Ley de Arbitraje, específicamente a aquellos cuya inobservancia justifican su anulación (artículo $63^{\circ}$ de la referida ley)? ¿O debemos comprender en ella a todos los criterios -tanto formales como materiales- que rigen la validez jurídica -en este caso de un laudoindependientemente de que estén recogidos o no en la Ley de Arbitraje (criterios que, como bien se sabe, se resumen en su producción por el órgano competente, el respeto al procedimiento preestablecido y la conformidad con la norma superior, especialmente con la Constitución)? El Tribunal Constitucional no ha dicho nada al respecto, por lo menos no en el precedente que aquí se examina. No obstante, como quiera que el control difuso de la constitucionalidad normativa es un mecanismo que garantiza la supremacía de la Constitución, sería absurdo fundamentar ese tipo de control en sede arbitral en el carácter supremo de esta Norma Fundamental (como lo hace el Tribunal Constitucional, lo hemos visto) y al mismo tiempo circunscribir su ámbito de actuación a las normas relacionadas con los requisitos de validez del laudo previstas en la Ley de Arbitraje. Sería un

16 Idem. 
absurdo porque bien podría ocurrir que una norma -relevante para la solución de un caso sometido a arbitraje- resulte incompatible con la Constitución sin que en modo alguno se refiera a alguno de esos requisitos legales. Si se establece que el control difuso puede ser aplicado en sede arbitral (como lo ha hecho el Tribunal Constitucional), entonces, no puede impedirse que sea utilizado para proteger la supremacía constitucional frente a una norma que, a pesar de ser relevante para la solución de la controversia sometida a arbitraje, resulta incompatible -por la forma o por el fondo- con la Constitución, independientemente de que esa norma guarde o no relación con alguno de los supuestos de anulación del laudo previstos en la Ley de Arbitraje. Por estas consideraciones, el control difuso, también en sede arbitral, puede ser aplicado, válidamente, sobre cualquier norma relevante para la solución de la controversia, y solo sobre ella (según la precisión que se desprende del precedente constitucional que aquí se examina). De ello depende, como es obvio, la validez del laudo, pues si este aplica una norma que, pese a ser relevante, es incompatible con la Constitución, el laudo sería nulo por infringir un criterio de validez jurídica, concretamente la exigencia de que sea conforme con la norma superior, en este caso con la Constitución.

Por otro lado, lo hemos visto, el Tribunal Constitucional ha señalado que para que se ejerza el control difuso en el arbitraje se debe verificar, además, que la norma en cuestión suponga un potencial "perjuicio claro y directo respecto al derecho de alguna de las partes"17. Se trata, nos parece, de una precisión correcta pero innecesaria, pues el solo hecho de que pueda aplicarse una norma incompatible con la Constitución, que incida de manera relevante en el resultado del arbitraje, supondrá siempre un potencial perjuicio directo a la parte que resulte desfavorecida con la resolución que aplique la norma, ya que -en tal caso- por lo menos se lesionaría su derecho a una decisión razonable que, como integrante del derecho fundamental a un debido proceso, exige que las resoluciones que se emitan sean válidas y, para que lo sean, las normas que apliquen no deben ser contrarias a la Constitución ${ }^{18}$. El potencial perjuicio sería directo porque la lesión al derecho a una decisión razonable se produciría por la sola aplicación de una norma que, aunque relevante, es incompatible con la Norma Fundamental. Debido a que el perjuicio directo a alguna de las partes se producirá siempre que se aplique a un caso concreto una norma legal que, pese a ser relevante, es incompatible con la Constitución, tal perjuicio directo se producirá independientemente de que la

17 Idem.

18 Explica el Tribunal Constitucional que «a partir del debido proceso también es posible un control que no es solo procesal o formal, sino también material o sustancial, respecto de la actuación jurisdiccional vinculado esta vez con la proporcionalidad y razonabilidad de las decisiones que emite en el marco de sus potestades y competencias" (Sentencia del Tribunal Constitucional. Exp. No 1209-2006-PA/TC, fundamento 29). Y agrega: «El debido proceso en su dimensión sustancial quiere significar un mecanismo de control sobre las propias decisiones y sus efectos, cuando a partir de dichas actuaciones o decisiones se afecta de modo manifiesto y grave cualquier derecho fundamental", con el objeto de evitar "zonas de intangibilidad para que la arbitrariedad o la injusticia puedan prosperar cubiertas con algún manto de justicia procedimental o formal" (Ibíd., fundamento 30). 
norma en cuestión se aplique en sede arbitral o judicial; por lo tanto, la exigencia de verificar este requisito vale tanto para el control difuso que se ejerce en sede arbitral como el que se ejerce en sede judicial, razón por la cual tampoco hay aquí modulación alguna.

Algo similar sucede con la exigencia de claridad en el perjuicio: si toda aplicación de una norma legal que contraviene la Constitución lesiona el derecho a una decisión razonable y, por ende, perjudica a su titular que no fue favorecido con esa decisión; la única posibilidad de que un perjuicio no sea claro es que la incompatibilidad entre esa norma legal y la Norma Fundamental no sea manifiesta. En tal caso, como lo recuerda el mismo precedente vinculante del Tribunal Constitucional que aquí se examina, se debe "obtener de ella [esto es, de esa norma legal] una interpretación conforme a la Constitución", vale decir, se debe reconducir la norma en cuestión, vía interpretación, a un sentido compatible con la Norma Fundamental ${ }^{19}$. Una exigencia que se deriva de la presunción de constitucionalidad atribuida a toda ley, la misma que encuentra sustento normativo, entre otros, en el artículo $103^{\circ}$ de la Constitución. Lo explica así el Tribunal Constitucional: “El principio de presunción de constitucionalidad de las normas establece que una ley no será declarada inconstitucional [y por la misma razón, tampoco inaplicada a un caso concreto] a menos que exista duda razonable sobre su absoluta y flagrante contradicción con la Constitución. Se trata de una presunción iuris tantum, por lo que, en tanto no se demuestre la abierta inconstitucionalidad de la norma, el juez constitucional [y por similar razón cualquier otro juzgador] estará en la obligación de adoptar una interpretación que la concuerde con el texto constitucional" 20 . Como quiera que esta exigencia tiene un origen constitucional que se aplica no solo al control concentrado (declaración de inconstitucionalidad de la ley) sino también al control difuso (inaplicación de la norma legal), vale tanto para el control difuso que se ejerce en sede arbitral como el que se ejerce en sede judicial, por esta razón tampoco aquí se aprecia modulación alguna.

iii. El control difuso es residual: se debe inaplicar la norma incompatible con la Constitución solo si no es posible reconducirla a través de la interpretación constitucional

Según la jurisprudencia del Tribunal Constitucional los árbitros -y los jueces en general- solo pueden ejercer el control difuso como última ratio: "Solo [se] inaplican las disposiciones que [se] estimen incompatibles con la Constitución cuando por vía interpretativa no sea posible la adecuación de tales normas al ordenamiento constitucional" 21 . Esto se debe, explica este alto Tribunal citando a su homólogo español, a que "la Constitución es un marco de coincidencias suficientemente amplio como para que dentro de él quepan opciones políticas de

19 Sentencia del Tribunal Constitucional. Exp. N 142-2011-PA/TC, fundamento 26.

20 Sentencia del Tribunal Constitucional. Exp. No 020-2003-AI/TC, fundamento 33.

21 Sentencia del Tribunal Constitucional. Exp. $N^{\circ} 1680-2005-P A / T C$, fundamentos 3 y 4. 
muy diferente signo. La labor de interpretación de la Constitución no consiste necesariamente en cerrar el paso a las opciones o variantes imponiendo autoritariamente una de ellas" 22 . En ese sentido, antes de ejercer el control difuso de la constitucionalidad de una norma legal -que se presente como incompatible con la Constitución- los árbitros deben agotar cualquier posibilidad de salvar la constitucionalidad de esa norma legal mediante una labor interpretativa que permita otorgarle un significado compatible con la Constitución. Solo si se verifica que ese resultado interpretativo es imposible de alcanzar, podrán ejercer el control difuso de la constitucionalidad normativa inaplicando la norma legal al caso concreto por su incompatibilidad con la Constitución.

Para realizar esa labor los árbitros deben interpretar la ley desde la Constitución (es decir, partiendo del contenido de los propios preceptos constitucionales) y conforme a la Constitución (verificando que el resultado interpretativo sea compatible con alguna de las opciones que razonablemente otorga el pluralismo de la Constitución). Lo recuerda el Tribunal Constitucional: “[...] en todo ordenamiento que cuenta con una Constitución rígida y, por tanto, donde ella es la fuente suprema, todas las leyes y disposiciones reglamentarias, a fin de ser válidamente aplicadas, deben necesariamente ser interpretadas "desde" y "conforme" con la Constitución"23. Por lo tanto, la interpretación de la ley y de cualquier otra norma jurídica en general -según parámetros constitucionalessupone la previa interpretación de la Constitución.

Y para interpretar la Constitución nuestro Tribunal Constitucional ha establecido sendos principios jurídicos que se deben seguir. Explica así esta situación: “Reconocida la naturaleza jurídica de la Constitución del Estado, debe reconocerse también la posibilidad de que sea objeto de interpretación. No obstante, la particular estructura normativa de sus disposiciones que, a diferencia de la gran mayoría de las leyes, no responden en su aplicación a la lógica subsuntiva (supuesto normativo - subsunción de hecho - consecuencia), exige que los métodos de interpretación constitucional no se agoten en aquellos criterios clásicos de interpretación normativa (literal, teleológico, sistemático e histórico), sino que abarquen, entre otros elementos, una serie de principios que informan la labor hermenéutica del juez constitucional". Y para identificar cuáles son estos principios, el Tribunal Constitucional señala que tales principios son:

“a) El principio de unidad de la Constitución: Conforme al cual la interpretación de la Constitución debe estar orientada a considerarla como un "todo" armónico y sistemático, a partir del cual se organiza el sistema jurídico en su conjunto.

b) El principio de concordancia práctica: En virtud del cual toda aparente tensión entre las propias disposiciones constitucionales debe ser resuelta "optimizando" su interpretación, es decir, sin "sacrificar" ninguno de los valores, derechos o

22 Sentencia del Tribunal Constitucional. Exp. № 0004-2004-AI/TC, fundamento 26.

23 Sentencia del Tribunal Constitucional. Exp. N 1230-2002-HC/TC, fundamento 4. 
principios concernidos, y teniendo presente que, en última instancia, todo precepto constitucional, incluso aquellos pertenecientes a la denominada "Constitución orgánica" se encuentran reconducidos a la protección de los derechos fundamentales, como manifestaciones del principio-derecho de dignidad humana, cuya defensa y respeto es el fin supremo de la sociedad y el Estado (artículo $1^{\circ}$ de la Constitución).

c) El principio de corrección funcional: Este principio exige al juez constitucional que, al realizar su labor de interpretación, no desvirtúe las funciones y competencias que el Constituyente ha asignado a cada uno de los órganos constitucionales, de modo tal que el equilibrio inherente al Estado Constitucional, como presupuesto del respeto de los derechos fundamentales, se encuentre plenamente garantizado.

d) El principio de función integradora: El "producto" de la interpretación solo podrá ser considerado como válido en la medida que contribuya a integrar, pacificar y ordenar las relaciones de los poderes públicos entre sí y las de estos con la sociedad.

e) El principio de fuerza normativa de la Constitución: La interpretación constitucional debe encontrarse orientada a relevar y respetar la naturaleza de la Constitución como norma jurídica, vinculante in toto y no solo parcialmente. Esta vinculación alcanza a todo poder público (incluyendo, desde luego, a este Tribunal) y a la sociedad en su conjunto" 24 .

Entre las consecuencias que se derivan de la aplicación de estos principios de interpretación constitucional se encuentra aquella que exige que la interpretación de una norma constitucional no se realice de manera aislada o atomista, sino que tenga en cuenta todos los principios y derechos constitucionales que guarden relación con el caso concreto a decidir. La razón es simple, "la Constitución como norma jurídica, [es] vinculante in toto y no solo parcialmente", por lo que no puede protegerse válidamente una norma constitucional omitiendo o desconociendo a las demás (principio de unidad de la Constitución) ${ }^{25}$. Siendo esto así, si un laudo efectuó el control difuso de alguna norma legal confrontándola única y exclusivamente con una norma constitucional (por ejemplo, el principio de negociación colectiva, previsto en el artículo $28^{\circ}$ de la Constitución), tal laudo habrá vulnerado el citado parámetro de interpretación constitucional, pues no consideró los demás preceptos constitucionales con los que aquella norma que utilizó para efectuar la comparación guarda relaciones de coordinación o complementariedad en el ordenamiento jurídico (verbigracia, el principio de equilibrio presupuestario del sector público, previsto en los artículos $77^{\circ}$ y $78^{\circ}$ de la Constitución).

Del mismo modo, si al efectuar el control difuso de una norma legal, un laudo resuelve un eventual conflicto de principios constitucionales a favor de uno de

24 Sentencia del Tribunal Constitucional. Exp. N 5854-2005-PA/TC, fundamento 12.

25 Idem. 
ellos, pero eliminando el contenido de los demás (es decir, restándoles toda virtualidad o eficacia para el caso concreto, al punto de convertirlos en meros enunciados sin relevancia alguna), entonces ese laudo habrá vulnerado otro parámetro de interpretación constitucional (el principio de concordancia práctica), deviniendo el control difuso así realizado -al igual que en el caso anterior- en una actuación contraria a la Constitución. La razón nuevamente es simple: al interpretar la Constitución toda aparente tensión entre las normas constitucionales debe resolverse a favor de aquella alternativa interpretativa que optimice, en la mayor medida posible, sus respectivos contenidos, "sin "sacrificar" ninguno de los valores, derechos o principios concernidos" 26 .

\section{iv. El control difuso requiere aplicar el test de ponderación}

En reiteradas ocasiones el Tribunal Constitucional ha establecido que solo se puede inaplicar una norma legal, en ejercicio del control difuso, si es que previamente se ha verificado que dicha norma no cumple con las exigencias derivadas de los principios de razonabilidad y proporcionalidad, también conocidas como el test de ponderación. Un test que debe aplicarse sobre la norma en cuestión, teniendo en cuenta los diversos bienes jurídicos constitucionales que guarden relación con el caso concreto a decidir. Lo ha recordado así a través de senda jurisprudencia: “Debe verificarse si la norma legal objeto de control difuso de constitucionalidad es manifiestamente incompatible con la Constitución, y si es así, disponerse su inaplicación al caso concreto. En tal verificación resultará de particular importancia identificar aquel contenido constitucionalmente protegido así como la manifiesta incompatibilidad de la norma legal respecto del mencionado contenido constitucional, procedimiento en el que resultará importante superar el control de proporcionalidad, entre otros que se estime pertinente, de modo que se argumente correctamente la decisión [...]"27.

Esto se debe a que los derechos fundamentales y los demás bienes jurídicos constitucionalmente protegidos -incluyendo el orden axiológico en el que se fundan- no se encuentran organizados jerárquicamente, lo cual hace que los conflictos que eventualmente puedan surgir entre sí no puedan resolverse con la afirmación genérica de la preferencia incondicionada o absoluta de alguno sobre los demás, sino mediante un juicio ponderativo que sopese los derechos y bienes involucrados sobre la base de que todos son iguales y equivalentes entre sí28. En ese escenario la ponderación (también llamada juicio de razonabilidad, proporcionalidad o interdicción de la arbitrariedad) es una técnica útil para determinar el contenido y resolver las situaciones de colisión de cualesquiera principios jurídicos (entendiendo por principios a aquellas normas jurídicas que

26 Ibíd.

27 Sentencia del Tribunal Constitucional. Exp. N 02132-2008-PA/TC, fundamento 26.

28 Cfr. SOLOZÁBAL ECHAVARRÍA, Juan José. “Algunas cuestiones básicas de la teoría de los derechos fundamentales". En Revista de Estudios Políticos-Nueva Época-, núm. 71, Enero-Marzo, p. 98. 
contienen mandatos de optimización o que carecen de supuestos de hecho o presentan de un modo fragmentario sus condiciones de aplicación), entre ellas las situaciones de colisión de los derechos fundamentales y demás bienes jurídicos constitucionalmente protegidos. La ponderación, consiste en considerar imparcialmente los aspectos contrapuestos de una cuestión y buscar la mejor decisión (por ejemplo, el mejor laudo o la mejor sentencia) cuando en la argumentación concurren distintas razones justificatorias de una u otra opción, pero contradictorias entre sí y del mismo valor. Se ponderan razones enfrentadas, derechos, intereses o bienes en conflicto, en suma, normas de igual valor que nos suministran justificaciones diferentes a la hora de adoptar una decisión ${ }^{29}$. Para ello se requiere que no exista entre las norma enfrentadas una relación de temporalidad, de jerarquía o de especialidad, ya que, de los contrario, los conflictos normativos que pudieran presentarse entre sí podrían resolverse con los criterios tradicionales de solución de antinomias: el jerárquico, el cronológico y el de especialidad, además del criterio de competencia o el de prevalencia.

La ponderación se realiza en el ámbito del discurso de aplicación y no en el de la validez ${ }^{30}$. Por ello, los eventuales conflictos que se pueden presentar entre los principios (derechos, bienes, etc.), al concurrir en un caso concreto, algunas veces se resolverán con el equilibrio entre todos ellos pero otras veces con el triunfo o la preferencia de alguno sobre los demás, solución que puede ser diferente ante otras circunstancias o en un diferente caso concreto. Lo explica la doctrina especializada: “Ciertamente, en el mundo del Derecho el resultado de la ponderación no ha de ser necesariamente el equilibrio entre tales intereses, razones o normas; en ocasiones tal equilibrio, que implica un sacrificio parcial y compartido, se muestra imposible y entonces la ponderación desemboca en el triunfo de alguno de ellos en el caso concreto. En cambio, donde sí ha de existir equilibrio es en el plano

29 PRIETO SANCHÍS, Luis. Justicia Constitucional y Derechos Fundamentales, Madrid: Trotta, 2003, p. 189.

30 Las antinomias abstractas o propias del discurso de validez se presentan cuando los supuestos de hecho descritos por dos o más normas -con consecuencias jurídicas diferentes- se superponen conceptualmente, de forma tal que siempre que se pretenda aplicar alguna de ellas se producirá el conflicto con las demás. En tal caso, o alguna norma no es válida u opera como una excepción permanente frente a las demás. Como quiera que en este tipo de casos las normas involucradas presentan condiciones de aplicación cerradas o suficientemente perfiladas, los conflictos normativos que se presentan entre sí suelen resolverse con los criterios tradicionales de solución de antinomias: el jerárquico, el cronológico, el de especialidad, etc.

En cambio, las antinomias en concreto o propias del discurso de aplicación se presentan cuando las condiciones de aplicación de las normas involucradas no aparecen cerradas o suficientemente perfiladas, al punto que no es posible definir en abstracto la contradicción ni conocer por adelantado los supuestos o casos de aplicación. Por lo tanto, no contamos con una regla segura para resolver los eventuales conflictos normativos que puedan surgir. Este tipo de antinomias, propias del discurso de aplicación, suele presentarse entre normas coetáneas y del mismo nivel jerárquico que, además, carecen de supuesto de hecho o condiciones de aplicación o han sido formuladas de tal manera que no es posible establecer cuál de ellas es una excepción frente a la otra (como ocurre con varios preceptos constitucionales). Allí no es posible aplicar el criterio cronológico ni el criterio jerárquico y mucho menos el criterio de especialidad para resolver las situaciones de conflicto normativo. En tales casos estos deben ser resueltos mediante otras técnicas o criterios correspondientes al discurso de aplicación (Cfr. PRIETO SANCHÍs, Ibíd., p. 179). 
abstracto o de la validez: en principio, han de ser todos del mismo valor, pues de otro modo no habría nada que ponderar; sencillamente, en caso de conflicto se impondría el de más valor" 31 .

No se trata, pues, de una fórmula infalible de solución de los conflictos normativos, y no podría serlo pues, a diferencia de los criterios tradicionales de solución de antinomias, en la ponderación se trabaja con normas de igual valor que presentan un alto grado de vaguedad o indeterminación. No obstante, la necesidad de su utilización se advierte desde el momento en que se acepta que no existe jerarquías internas entre los derechos fundamentales y demás bienes jurídicos constitucionalmente protegidos o, en general, entre los principios jurídicos sobre los cuales trabaja, siendo su principal virtud el estimular una interpretación y una decisión que tenga presente la tutela de todos los derechos o bienes jurídicos involucrados, bajo la premisa de que todos ellos poseen una vocación de máxima realización compatible con la máxima realización de los demás ${ }^{32}$.

La ponderación ha sido objeto de una elaboración jurisprudencial y doctrinal importante ${ }^{33}$. En el Perú el Tribunal Constitucional viene utilizándolo y ha fijado con nitidez los pasos a seguir o las exigencias concretas que comprende, siendo conocidas como "exigencias de la ponderación", "test de la proporcionalidad" o "exigencias de razonabilidad", etc., tal como las describimos a continuación.

Para empezar, la ponderación "se opone a lo arbitrario y remite a una pauta de justicia"34, exigiendo que cualquier norma o decisión que involucre a derechos fundamentales o bienes constitucionales responda a un fin constitucionalmente legítimo y que los medios utilizados para conseguirlo sean proporcionales (tanto desde la perspectiva del bien o valor que tutela, como desde la perspectiva del bien o valor que limita o regula). Si una norma o decisión que involucra derechos o bienes constitucionales no persigue un fin constitucionalmente legítimo o no es proporcional, entonces, será una norma o decisión contraria a la Constitución.

La exigencia del fin constitucionalmente legítimo, como primera exigencia o paso a seguir en la ponderación, significa que cualquier medida o decisión que involucre a los derechos o bienes constitucionales debe ser razonable, esto es, debe perseguir una finalidad que responda a causas objetivas de justificación y resulte legítima desde la propia perspectiva constitucional. Por ejemplo, debe responder a la función y naturaleza del derecho sobre el cual se incide o a la necesidad de proteger otro derecho fundamental $\mathrm{u}$ otro bien jurídico constitucionalmente protegido. Por lo tanto, "si no existe tal fin y la actuación pública es gratuita, o si resulta ilegítimo desde la propia perspectiva constitucional, entonces no hay nada

31 PRIETO SANCHÍS, Ibíd., p. 189.

32 PRIETO SANCHÍS, Ibíd., pp. 190-191.

33 Es ejemplo de ello el trabajo de BERNAL PULIDO, Carlos., El principio de proporcionalidad y los derechos fundamentales. Madrid: Centro de Estudios Políticos y Constitucionales, 2003.

34 BIDART CAMPOS, Germán. J. La Corte Suprema -El Tribunal de las Garantías Constitucionales-. Buenos Aires: Ediar, 1984, p. 108. 
que ponderar porque falta uno de los términos de la comparación" 35 . Nuestro Tribunal Constitucional lo explica de esta manera: “[...] por virtud del principio de razonabilidad se exige que la medida restrictiva se justifique en la necesidad de preservar, proteger o promover un fin constitucionalmente valioso. Es la protección de fines constitucionalmente relevantes la que, en efecto, justifica una intervención estatal en el seno de los derechos fundamentales. Desde esta perspectiva, la restricción de un derecho fundamental satisface el principio de razonabilidad cada vez que esta persiga garantizar un fin legítimo y, además, de rango constitucional" 36 .

Por otro lado, la exigencia de proporcionalidad, como segundo paso a efectuar en la ponderación, exige que los medios empleados para alcanzar el fin perseguido sean necesarios, adecuados y proporcionales en sentido estricto; es decir, que además de ser imprescindibles e idóneos para alcanzarlo, exista una adecuada correspondencia, armonía o proporción entre la limitación, regulación o decisión y el fin que pretende alcanzarse. Conforme a ello, el análisis de proporcionalidad de la norma o decisión involucrada debe efectuarse tanto desde la perspectiva del bien o derecho que tutela, como desde la perspectiva del bien o derecho que limita o lesiona. En palabras de nuestro Tribunal Constitucional, el presupuesto para la aplicación de esta exigencia de proporcionalidad "es siempre la presencia de dos principios constitucionales en conflicto y una decisión que afecta alguno de estos principios o bienes constitucionales. De este modo, la aplicación del principio de proporcionalidad debe suministrar elementos para determinar si la intervención en uno de los principios o derechos en cuestión, es proporcional al grado de satisfacción que se obtiene a favor del principio o valor favorecido con la intervención o restricción. El test [superada la exigencia del fin constitucionalmente legítimo] está compuesto por tres sub principios: idoneidad, necesidad y ponderación o proporcionalidad en sentido estricto" ${ }^{\prime 37}$. Veamos cada uno de ellos:

En primer lugar, la exigencia de idoneidad, en base a la cual se hace un control de adecuación sobre la medida o decisión que interviene en los derechos fundamentales o bienes constitucionales a fin de determinar si reúne las condiciones necesarias para alcanzar la finalidad perseguida con ella. Una medida es inadecuada cuando dificulta el alcance de la finalidad proyectada o cuando no desarrolla ningún efecto en relación al fin de la medida. Si una medida no puede alcanzar o no es adecuada para el fin que persigue entonces resultará desproporcionada y, por lo tanto, constitucionalmente ilegítima ${ }^{38}$. Dicho de otra manera, "la actuación que afecte a un principio o derecho constitucional ha de mostrarse consistente con el bien o con la finalidad en cuya virtud se establece. Si

\footnotetext{
PRIETO SANCHÍS, Op. cit., p. 199.

Sentencia del Tribunal Constitucional. Exp. N 1209-2006-PA/TC, fundamento 54.

Ibíd., fundamento 55.

38 Véase en: ALEXY, Robert. Teoría de los derechos fundamentales, traducción de E. Garzón Valdés, Madrid: Centro de Estudios Constitucionales, 1994, p. 114.
} 
esa actuación no es adecuada para la realización de lo prescrito en una norma constitucional, ello significa que para esta última resulta indiferente que se adopte o no la medida en cuestión; y entonces, dado que sí afecta, en cambio, a la realización de otra norma constitucional, cabe excluir la legitimidad de la intervención"39. Lo dice así el mismo Tribunal Constitucional: "En cuanto al procedimiento que debe seguirse en la aplicación del test de proporcionalidad, hemos sugerido que la decisión que afecta un derecho fundamental debe ser sometida, en primer término, a un juicio de idoneidad o adecuación, esto es, si la restricción en el derecho resulta pertinente o adecuada al fin propuesto" 40 .

En segundo lugar, la exigencia de necesidad manda efectuar un control sobre el carácter imprescindible de la intervención o limitación del derecho o bien jurídico constitucional. Se trata de determinar que no exista otra medida igualmente efectiva y adecuada para alcanzar el fin perseguido, pero distinta de la utilizada, que suponga una menor restricción para el derecho fundamental o bien jurídico constitucional que se afecta, pues de lo contrario dicha medida sería desproporcionada. Para su aplicación es necesario determinar el peligro, amenaza o perjuicio para el bien jurídico protegido y, en segundo lugar, constatar que dicho perjuicio es el menor posible ${ }^{41}$. Esto significa que si la consecución de una finalidad constitucionalmente legítima puede lograrse a través de una pluralidad de medidas, es imperativo escoger aquella que menos perjuicios cause al derecho fundamental o bien jurídico constitucional que limita. Lo explica así nuestro Tribunal Constitucional: “[...] en segundo lugar, superado este primer análisis [de la idoneidad], el siguiente paso consiste en analizar la medida restrictiva desde la perspectiva de la necesidad; esto supone como hemos señalado, verificar "si existen medios alternativos al optado" [...]. Se trata del análisis de relación mediomedio, esto es, de una comparación entre medios; el medio elegido por quien está interviniendo en la esfera de un derecho fundamental y el o los hipotéticos medios que hubiera podido adoptar para alcanzar el mismo fin" 42 .

Por último, la proporcionalidad, y por ende el juicio de ponderación, se completa con la llamada exigencia de proporcionalidad en sentido estricto, en virtud de la cual se procura determinar si la carga o el límite que supone la medida o actuación en el derecho fundamental, o bien jurídico constitucionalmente protegido, es razonable o proporcional en comparación con la finalidad perseguida. Dicha carga será más razonable o proporcional cuanto más importante sea para la protección del derecho o bien jurídico que protege, o para la defensa frente a los eventuales perjuicios que pueda ocasionar el ejercicio del derecho fundamental o la actuación del bien jurídico constitucional sobre el cual incide. En otras palabras, "consiste en acreditar que existe un cierto equilibrio entre los beneficios que se obtienen con la

39 PRIETOSANCHÍS, Op. cit., p. 200.

40 Sentencia del Tribunal Constitucional. Exp. N 1209-2006-PA/TC, fundamento 56.

41 Véase en.: ALEXY, Op. cit., p. 113.

42 Sentencia del Tribunal Constitucional. Exp. N 1209-2006-PA/TC, fundamento 56. 
medida limitadora o con la conducta de un particular en orden a la protección de un bien constitucional o a la consecución de un fin legítimo, y los daños o lesiones que de dicha medida o conducta se derivan para el ejercicio de un derecho o para la satisfacción de otro bien o valor; aquí es donde propiamente rige la ley de ponderación, en el sentido de que cuanto mayor sea la afectación producida por la medida o por la conducta en la esfera de un principio o derecho, mayor o más urgente ha de ser también la necesidad de realizar el principio en pugna" 43 . Nuestro Tribunal Constitucional lo explica en estos términos: "Finalmente, en un tercer momento y siempre que la medida haya superado con éxito los test o pasos previos, debe proseguirse con el análisis de la ponderación entre principios constitucionales en conflicto. Aquí rige la ley de la ponderación, según la cual 'cuanto mayor es el grado de la no satisfacción o de la afectación de un principio, tanto mayor tiene que ser la importancia de la satisfacción del otro'“44.

Recapitulando, el juicio de ponderación permite analizar la legitimidad constitucional de las normas o decisiones que inciden sobre los derechos fundamentales y demás bienes jurídicos constitucionalmente protegidos, sirviendo además como juicio valorativo para solucionar los eventuales conflictos que puedan surgir entre este sí al concurrir en un caso concreto. Si se inaplica una norma legal -en ejercicio del control difuso- sin que previamente se haya verificado que dicha norma no cumple con las exigencias derivadas del test de ponderación (razonabilidad y proporcionalidad), y resultare que esa norma sí cumple con esas exigencias; entonces, resulta evidente que esa inaplicación resultará inválida y el control difuso, así ejercido, una desviación del poder.

\section{v. La exigencia de una motivación adecuada}

En vista de que el control difuso supone un juicio de ponderación, y atendiendo a que este se opone a lo arbitrario, el resultado del control difuso no puede ser el producto de la mera voluntad de quien efectúa ese control, es decir, una simple

43 PRIETOSANCHÍS, Op. cit., p. 202. Este autor advierte que cuando la proporcionalidad en sentido estricto se hace valer en el enjuiciamiento de normas generales y más concretamente de leyes, «el carácter consecuencialista del argumento bien podría desembocar en una ablación, en una eliminación absoluta de uno de los principios en pugna, y ello ocurrirá cuando la necesidad y la urgencia de atender a un fin valioso e importante mostrase como justificada la postergación general de otro bien o derecho. En materia de derechos fundamentales, ésta es una consecuencia que puede evitarse a través de la cláusula del contenido esencial, pues cualquiera que sea su discutido alcance, debe al menos servir como contrapunto a los argumentos ponderativos; sería algo así como la traducción jurídica de la vieja pretensión de los derechos de situarse como derechos absolutos, al margen del regateo político y del cálculo de intereses sociales, por importantes que éstos puedan ser. Pero, con carácter general, existe otro argumento contra la posible eliminación o lesión absoluta de algún principio constitucional que deriva del propio carácter de la ponderación; y es que ésta ha de partir y ha de culminar en la preservación de todas las normas constitucionales consideradas en abstracto, en el nivel de la validez, sin cancelar en ese nivel su tendencial conflicto, y una ley que afectase de modo definitivo al núcleo de algún principio, aun cuando justificada en una perspectiva consecuencialista, equivaldría a una jerarquización o al establecimiento de una cláusula de excepción a favor de algún bien constitucional; y ello, como hemos indicado, supondría una tarea constituyente" (Ibíd., pp. 202203).

44 Sentencia del Tribunal Constitucional. Exp. N 1209-2006-PA/TC, fundamento 56. 
consecuencia de su subjetividad o de su particular apreciación de la vida. Tampoco puede ser el producto de un razonamiento absurdo o defectuoso. Por el contrario, el control difuso debe ser acompañado de un razonamiento correcto expuesto a través de una motivación adecuada, es decir, de una motivación que no sea aparente o defectuosa, de una argumentación que exponga en forma clara, lógica y suficiente los fundamentos que justifican esa medida o decisión. Esto con el propósito de que los destinatarios o interesados conozcan las razones y los intereses por las cuales se optó por tal o cual decisión al efectuar el control.

No estamos afirmando que las exigencias que conforman el derecho a una motivación adecuada resulten exigibles tan solo al ejercer el control difuso. Ellas resultan aplicables en diversos ámbitos del ordenamiento jurídico y encuentran sustento en el derecho fundamental a un debido proceso. No en vano el Tribunal Constitucional ha señalado que "el debido proceso comprende, a su vez, un conjunto de derechos constitucionales que forman parte de su estándar mínimo, entre los cuales se encuentra el derecho a la motivación" 45 . Como bien precisa este Tribunal, el derecho a la motivación no se satisface con cualquier tipo de fundamentación, sino con una que sea adecuada, es decir que no sea aparente, defectuosa ni insuficiente. En ese sentido, establece: "Se viola el derecho a una decisión debidamente motivada cuando la motivación es inexistente o cuando la misma es solo aparente, en el sentido de que no da cuenta de las razones mínimas que sustentan la decisión o de que no responde a las alegaciones de las partes del proceso o porque solo intenta dar cumplimiento formal al mandato, amparándose en frases sin sustento fáctico o jurídico" 46 . Se trata de una de las garantías más útiles para evitar la arbitrariedad o el absurdo en el que puede incurrir el juzgador, o cualquier otra autoridad, a la hora de tomar una decisión que incida sobre el estatuto o la esfera de las personas, o demás sujetos en general, sobre todo en cuanto a los derechos fundamentales y demás bienes constitucionales se refiere.

Por ello, cuando un árbitro -o un juez- ejerce el control difuso de la constitucionalidad normativa debe exponer en forma adecuada las razones que lo llevaron a adoptar la correspondiente decisión, de tal suerte que pueda verificarse su validez. De no ser así, si la motivación es inexistente o resulta aparente, defectuosa o arbitraria, se quitaría legitimidad constitucional a esa decisión.

\section{vi. La revisión judicial de la decisión arbitral frente al ejercicio indebido del control difuso}

Para terminar, recordemos que el tránsito del Estado legal al Estado constitucional de Derecho supuso, entre otros aspectos, abandonar la vieja tesis según la cual la Constitución no era más que un simple código político -sin fuerza jurídica algunapara convertirse en una auténtica norma jurídica de la mayor jerarquía. Esto

45 Sentencia del Tribunal Constitucional. Exp. $N^{\circ}$ 03122-2012-PA/TC, fundamento 3.3.1.

46 Sentencia del Tribunal Constitucional. Exp. $\mathrm{N}^{\circ}$ 00728-2008-PHC/TC, fundamento 7. 
significa que la Constitución actualmente es -entre otras cosas-el principal criterio de validez de todo acto de poder, incluyendo un laudo arbitral o una sentencia. Si un laudo o una sentencia son contrarios a la Constitución, irremediablemente son inválidos: no pueden surtir efectos jurídicos. Lo destaca el Tribunal Constitucional: “[En el] Estado constitucional de Derecho [...] todo poder devino entonces en un poder constituido por la Constitución y, por consiguiente, limitado e informado, siempre y en todos los casos, por su contenido jurídico-normativo"; debido a que “la Constitución preside el ordenamiento jurídico (artículo 51º, [...] ningún acto de los poderes públicos (artículo $45^{\circ}$ ) o de la colectividad en general (artículo $38^{\circ}$ ) puede vulnerarla válidamente" 47 . Por ese mismo motivo, en un Estado constitucional de Derecho -como lo es el peruano- ningún laudo ni cualquier otro acto de poder están exentos de control constitucional. Lo ha reiterado el Tribunal Constitucional a través de una vasta jurisprudencia: “En un Estado Constitucional de Derecho no existen (ni pueden auspiciarse) zonas exentas de control constitucional, más allá de aquellas que la propia Constitución pueda haber establecido con carácter excepcional" 48 .

Estas consecuencias alcanzan al arbitraje. Lo refirma el mismo Tribunal: “La naturaleza de jurisdicción independiente del arbitraje, no significa que establezca el ejercicio de sus atribuciones con inobservancia de los principios constitucionales"49. Y agrega: "Ello es así por cuanto la función jurisdiccional se sustenta y se debe a la norma fundamental, más allá de la especialidad sobre la que pueda versar o de la investidura de quienes la puedan ejercer. De este modo y aunque se dota a la justicia arbitral de las adecuadas garantías de desenvolvimiento y se fomenta su absoluta observancia, la misma se encuentra inevitablemente condicionada a que su ejercicio se desarrolle en franco respeto al orden constitucional y a los derechos de la persona"50. Y ampliando su explicación, en otro momento el Tribunal Constitucional indica: “La Constitución es la norma de máxima supremacía en el ordenamiento jurídico y, como tal, vincula al Estado y la sociedad en general. De conformidad con el artículo $38^{\circ}$ de la Constitución, “Todos los peruanos tienen el deber [...] de respetar, cumplir [...] la Constitución". Esta norma establece que la vinculatoriedad de la Constitución se proyecta erga omnes, no solo al ámbito de las relaciones entre los particulares y el Estado, sino también a aquéllas establecidas entre particulares. [...]. En consecuencia, cualquier acto proveniente de una persona natural o persona jurídica de derecho privado, que pretenda conculcar [las normas constitucionales...], resulta inexorablemente inconstitucional" 51 .

Al ser inválidos los actos de poder que vulneran la Constitución -aun cuando se traten de un laudo o una sentencia-, esa invalidez no puede ser omitida ni salvada

Sentencia del Tribunal Constitucional. Exp. N 5854-2005-PA/TC, fundamentos 3 y 6.

48 Sentencia del Tribunal Constitucional. Exp. N 1230-2002-HC/TC, fundamento 5.

49 Sentencia del Tribunal Constitucional. Exp. N 6167-2005-PHC/TC, fundamento 9.

50 Sentencia del Tribunal Constitucional. Exp. N 142-2011-PA/TC, fundamento 11.

51 Sentencia del Tribunal Constitucional. Exp. N 1124-2001-AA/TC, fundamento 6. 
por el juzgador. Antes bien, debe ser declarada como parte de la tutela jurisdiccional a favor del afectado y en garantía de los preceptos constitucionales vulnerados. Solo así se garantizará la suprema fuerza normativa de la Constitución. El Tribunal Constitucional lo explica: “La judicialización de la Constitución o, para ser más exactos, la de todo acto que a ella contravenga, es la máxima garantía de que su exigibilidad y la de los derechos fundamentales reconocidos, no está sujeta a los pareceres de intereses particulares; por el contrario, todo interés individual o colectivo, para ser constitucionalmente válido, debe manifestarse de conformidad con cada una de las reglas y principios, formales y sustantivos, previstos en la Carta Fundamental" 52.

Por tales fundamentos, resulta jurídicamente procedente solicitar al órgano competente del Poder Judicial (e incluso, en última instancia, al Tribunal Constitucional) tutela jurisdiccional para que invalide un laudo que, al ejercer el control difuso de la constitucionalidad normativa, vulneró los parámetros constitucionales que rigen tal tipo de control. Ese pedido no tiene por objeto que se revise el fondo mismo del asunto resuelto en el arbitraje, revisión que se encuentra prohibida por la ley (por ejemplo, si el arbitraje versó sobre la nulidad de un contrato, la solicitud de tutela no tiene por objeto que se verifique si el contrato es nulo o no), sino tan solo que se someta al laudo a un control constitucional a fin de verificar que vulneró la Constitución en el ejercicio del control difuso. Por esa razón, al solicitar la revisión no debe buscarse que el órgano jurisdiccional que efectuará la revisión se pronuncie sobre la pretensión contenida en la demanda arbitral que el laudo resolvió. Lo que debe buscarse -únicamentees que dicho órgano jurisdiccional verifique que el laudo vulneró la Constitución $\mathrm{y}$, tras esa verificación, anule el laudo para que sean los propios árbitros quienes resuelvan nuevamente el fondo del asunto -de ser el caso - pero esta vez sin las vulneraciones constitucionales en las que incurrieron. En términos más simples, lo que se busca y debe buscarse es que se tutele jurisdiccionalmente la mayor fuerza normativa de la Constitución.

La Corte Suprema de Justicia de la República ha reconocido este acierto al señalar que la declaración de nulidad de un laudo -verbigracia, por contravenir la Constitución- no supone revisar el fondo mismo del asunto resuelto en el arbitraje, sino únicamente ejercer el control jurisdiccional de la validez del laudo, conforme a lo previsto en la ley. Lo ha dicho en estos términos: “[...] el hecho de haber sometido a análisis los distintos extremos del laudo dictado por el tribunal arbitral [...] no constituye una infracción al principio de irrevisibilidad del criterio arbitral, pues al hacerlo la Sala Superior no ha tenido como propósito avocarse a la decisión sobre el fondo de la controversia, sino únicamente determinar [...] si se habían configurado las causales de invalidez invocadas en el recurso de anulación"; por lo que la Corte Suprema finaliza diciendo: “Esto último se hace más evidente aún

52 Sentencia del Tribunal Constitucional. Exp. N 5854-2005-PA/TC, fundamento 8. 
al observar que en la sentencia objeto de casación la Sala Superior no emite ningún tipo de pronunciamiento sobre la suerte que deba merecer el fondo de la controversia debatida [en el arbitraje] [...] sino que se limita a declarar la nulidad del laudo impugnado y reenvía una vez más la causa al tribunal arbitral para la emisión de un nuevo laudo" 53 .

53 CORTE SUPREMA DE JUSTICIA DE LA REPÚBLICA. Casación N 4645-2015-Lima, de 3 de noviembre de 2016, considerandos 28-29. 